\title{
Interactions Between Audition and Cognition in Hearing Loss and Aging
}

\author{
Chad S. Rogers and Jonathan E. Peelle
}

Department of Otolaryngology, Washington University in St. Louis, St. Louis MO USA

To appear as:

Rogers CS, Peelle JE (Submitted) Interactions between audition and cognition in hearing loss and aging. In: The Auditory Cognitive Neuroscience of Speech Perception (Springer Handbook of Auditory Research) (Holt and Lotto, eds). Springer.

\section{Dr. Chad Rogers \\ Department of Psychology}

Union College

Bailey Hall, 807 Union Street

Schenectady, NY 12308

email: rogersc@union.edu
Dr. Jonathan Peelle Department of Otolaryngology Washington University in Saint Louis 660 South Euclid, Box 8115

Saint Louis, MO 63110

email: jpeelle@wustl.edu

Keywords: listening effort, background noise, speech perception, cognitive aging, sentence comprehension, neuroimaging, cingulo-opercular network, executive attention, pupillometry, fMRI 
Abstract

47 Understanding spoken language requires transmission of the acoustic signal up the ascending 48 auditory pathway. However, in many cases speech understanding also relies on cognitive

49 processes that act on the acoustic signal. One area in which cognitive processing is particularly

50 striking during speech comprehension is when the acoustic signal is made less challenging,

51 which might happen due to background noise, talker characteristics, or hearing loss. This chapter

52 focuses on the interaction between hearing and cognition in hearing loss in aging. The chapter

53 begins with a review of common age-related changes in hearing and cognition, followed by

54 summary evidence from behavioral, pupillometric, and neuroimaging paradigms that elucidate

55 the interplay between hearing ability and cognition. Across a variety of experimental paradigms,

56 there is compelling evidence that when listeners process acoustically challenging speech,

57 additional cognitive processing is required compared to acoustically clear speech. This increase

58 in cognitive processing is associated with specific brain networks, with the clearest evidence

59 implicating the cingulo-opercular and executive attention networks and prefrontal cortex.

60 Individual differences in hearing and cognitive ability thus determine the cognitive demand faced

61 by a particular listener, and the cognitive and neural resources needed to aid in speech

62 perception.

63 
65 It goes without saying that the auditory system is of key importance for speech perception.

66 However, a number of recent frameworks for speech understanding have emphasized the

67 important additional contributions of cognitive factors (Wingfield et al. 2005; Pichora-Fuller et

68 al. 2016; Peelle In press). Although there are many reasons to consider cognitive processing in

69 speech perception, one especially important catalyst has been the longstanding realization that

70 hearing sensitivity, alone, is unable to fully account for speech understanding challenges faced

71 by listeners, particularly in noise (Plomp and Mimpen 1979; Humes et al. 2013). One

72 explanation for this finding is that current tests of auditory function may be lacking, and that

73 more informative tests are needed. However, another possibility is that individual differences in

74 cognitive ability contribute to a listener's relative success understanding speech. Thus, clarifying

75 the cognitive challenges associated with understanding acoustically-challenging speech is not

76 only of theoretical importance, but may significantly improve our understanding of

77 communication in everyday situations.

Hearing loss affects listeners of all ages, and in the United States is estimated to affect $23 \%$ of those aged 12 or older (Goman and Lin 2016). The focus of this chapter is primarily on

80 age-related hearing loss, given the particularly high incidence of hearing loss in adults over the

81 age of 65 (Cruickshanks et al. 1998; Mitchell et al. 2011). Healthy older adults are also a prime

82 group of listeners in whom to study the interactions of sensory and cognitive factors, given that

83 changes in both of these areas are frequently seen as we age.

Figure 1 shows a schematic of speech comprehension that includes processing related to auditory, language, and memory systems (because we frequently would like to remember what we have heard), as well as domain-general cognitive processes that act on one or more of these stages. The sections below cover a number of these areas where age-related changes are reported, as well as others that seem to be relatively preserved in older age. An important point to keep in mind is that there is significant variability in individual ability in all of these domains.

The first section of this review highlights the most salient age-related changes in hearing and cognition. Following this, the ways in which these changes manifest during speech comprehension and inform broader understanding of auditory-cognitive interaction are

93 examined. 


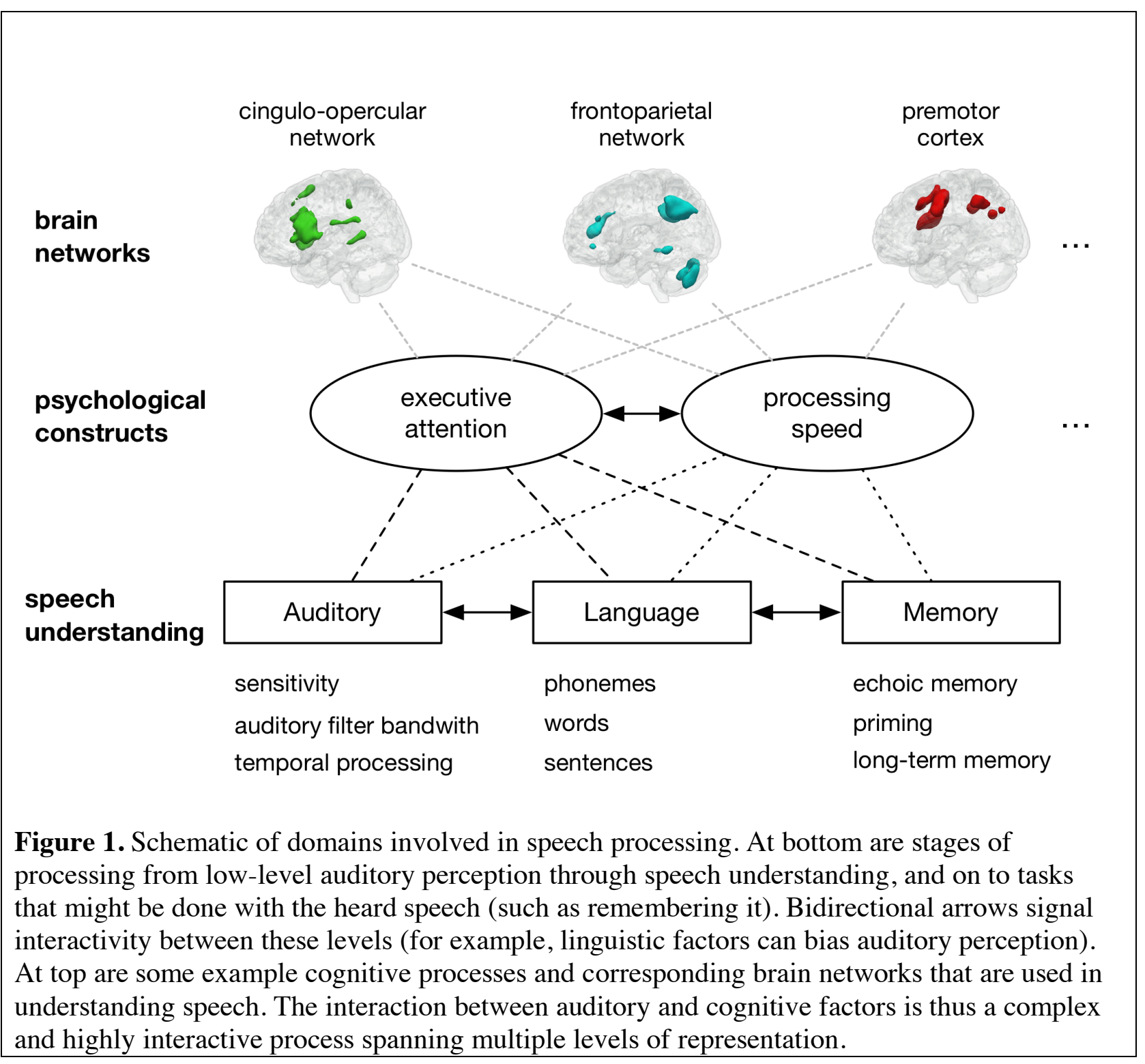

\section{Age-related Hearing Loss}

97 Age-related hearing loss is extremely common: Although estimates vary, some 40-50\% of adults over the age of 65 years have a measureable hearing impairment, with this number rising to greater than $80 \%$ of those over the age of 70 years (Cruickshanks et al. 1998). Age-related

100 changes in hearing occur at every level of the auditory system (Peelle and Wingfield 2016), and

101 the specific etiology is likely to have consequences for information processing. Age-related

102 hearing loss can be broadly categorized into peripheral hearing loss (having to do with the

103 cochlea) or central changes (having to do with the auditory nerve, subcortical structures, or

104 cortex). 


\subsection{Peripheral Changes in Hearing}

A major cause of age-related hearing loss is a reduction in the number of outer hair cells of the cochlea. For reasons that are still not entirely clear, hair cell loss occurs primarily in the basal end of the cochlea responsible for encoding high frequency information (Merchant and Nadol 2010). Thus, the most striking characteristic of age-related hearing loss is a decrease in sensitivity to higher frequencies. Figure 2 shows median pure-tone sensitivity for adults of different ages, illustrating this characteristic pattern, as well as the characteristically poorer hearing of men relative to women in older age. Fortunately, hearing in the range most important for speech information ( $4 \mathrm{kHz}$ and below) is generally relatively well preserved in cases of mild age-related hearing loss. However, some speech information (such as fricatives) can still be lost (Bilger and Wang 1976; Scharenborg et al. 2015), and as hearing sensitivity worsens it can affect speech intelligibility.

Changes to peripheral hearing can also be caused by synaptic dysfunction and degeneration of cochlear nerve axons. In animal models, Kujawa and Liberman (2009) found that a single noise exposure can weaken cochlear afferent nerve terminals. This weakening was observed even when there was no apparent damage to hair cells, or evidence of a long-term threshold shift. Because these changes are not always evident in pure-tone thresholds, they are often referred to as "hidden" hearing loss. Although still a relatively new area, there is growing evidence that hidden hearing loss contributes to deficits in amplitude modulation coding (Paul et al. 2017) and temporal processing (Bharadwaj et al. 2015).

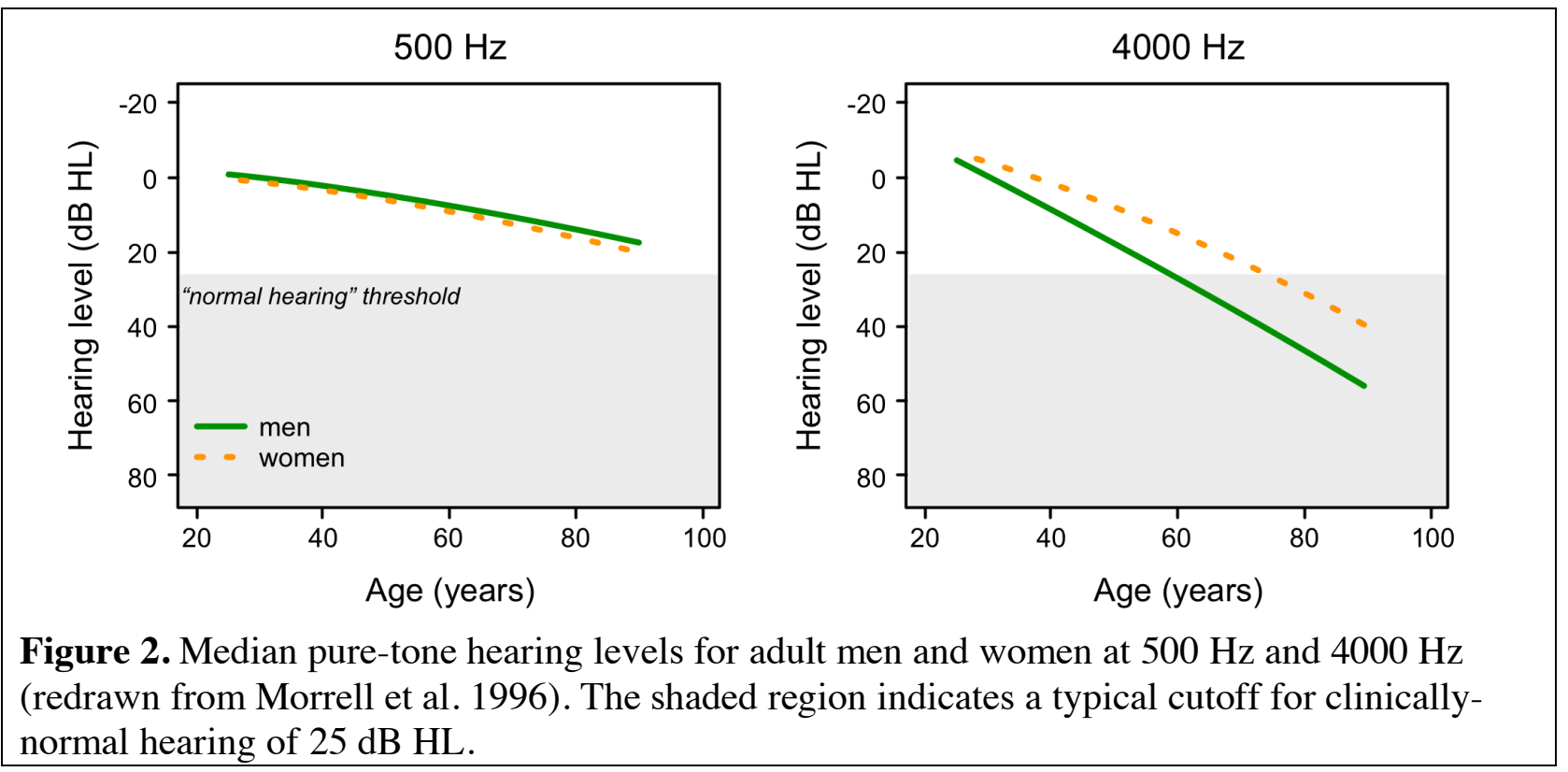

\subsection{Central Changes in Hearing}

128 Data from both animal and human studies suggest age-related changes in spiral ganglion neurons

129 (Bao and Ohlemiller 2010), cochlear nuclei, the superior olivary complex, and inferior colliculus

130 (Caspary et al. 2008; Engle et al. 2014). In humans, much work has focused on age-related

131 changes to the auditory brainstem response (ABR). The ABR is a time-locked

132 electrophysiological response elicited by brief acoustic stimuli (e.g., clicks, or a phoneme), 
133 typically recorded from EEG electrodes placed on the scalp. The amplitude and timing of the 134 peaks of the ABR can thus be used to infer the fidelity of subcortical auditory processing. With advancing age, the peaks of the ABR show reduced amplitude, and some peaks show additional delays in their timing relative to stimulus onset (Skoe et al. 2015). Aging is associated with decreased precision of the ABR including longer delays and greater variability across trials (Anderson et al. 2012). Changes in speech-evoked ABRs are also evident in listeners with hearing loss, suggesting that subcortical representations may contribute to speech-in-noise perception (Anderson et al. 2013).

Age-related changes are also evident in primary auditory cortex, reflected in both anatomy and electrophysiology. Parvalbumin is a calcium-binding protein expressed in auditory interneurons important for novelty detection and stimulus sensitivity. The number of parvalbumin-containing neurons is reduced in aging, and accompanied by reduced myelin (de Villers-Sidani et al. 2010; del Campo et al. 2012). Aging is also associated with a reduction in GAD, a GABA synthetic enzyme, in layers II-IV, probably reflecting a reduction in GABA levels (Ling et al. 2005; Burianova et al. 2009). Reports using magnetic resonance spectroscopy suggest some evidence consistent with the animal literature (Profant et al. 2013; Gao et al. 2015). Functionally, layer V neurons appear to show clear evidence for receptive field tuning (Turner et al. 2005; Hughes et al.2010), as well as changes in both evoked and spontaneous firing in superficial layers of auditory cortex (Kamal et al. 2013; Henry et al. 2014). Noninvasive electrophysiological studies in humans suggest numerous changes in the function of auditory cortex, including the magnitude of auditory evoked responses (Alain et al. 2014) and altered dynamics of stimulus adaptation (Herrmann et al. 2016). Finally, on a gross anatomical level, the volume of gray matter in auditory cortex is reduced in older adults with hearing loss (Peelle et al.

2011; Eckert et al. 2012). These observed macroanatomical structural changes may reflect changes in lower-level physiology associated with altered auditory processing.

\section{Cognition in Older Adulthood}

In addition to age-related changes to peripheral and central auditory structures that impact

160 hearing, age-related changes to cognitive abilities are well documented (Salthouse 1991; Balota

161 et al. 2000). However, it is crucial to emphasize that some cognitive systems important for

162 speech understanding clearly decline with age, whereas others do not (Park et al. 1996). The

163 differing consequences of aging for dissociable cognitive systems can elucidate the

164 consequences of aging on speech perception, but also help us better understand the underlying

165 bases for speech processing in other populations of listeners (such as healthy young adults). The

166 sections below highlight several cognitive systems closely related to speech understanding, and

167 their potential for age-related decline.

\section{3.1 Age-related Cognitive Decline}

169 Age-related changes are observed in many domains of cognition, only a few of which are 170 reviewed here. Because age-related changes are correlated across a large number of tasks, age171 related change is frequently thought of in a factor-analytic framework: that is, changes in many 172 specific cognitive systems can be explained by declines in a domain-general processing.

173 Common domain-general constructs have included executive attention and processing speed 174 (Salthouse 1996b; McCabe et al.2010), but regardless of the specific term, age-related changes 
have consistently been demonstrated is in tasks that rely on attentional control processes such as goal-maintenance, selective attention, and inhibition of task-irrelevant information (Braver and Barch 2002). As discussed throughout this section, changes in broad domain-general areas can also impact specific domains such as episodic memory or metacognition.

\subsubsection{Processing speed}

Age-related changes to processing speed, or the rate at which tasks are performed, are ubiquitous in aging research. Meta-analyses have revealed in virtually every timed task that older adults have slower mean reaction times than young adults (Cerella 1985; Verhaeghen and De Meersman 1998). These findings have led to an influential theory of general slowing in the cognitive aging literature (Salthouse 1996b), whereby age-related decline on cognitive tasks are considered the result of cascadic failures of cognitive operations to complete on time. Evidence in support of this theory includes large-scale psychometric studies and meta-analyses that assess covariation among tasks assessing processing speed, memory, and executive attention, and find that the two-way relationships between aging and memory or aging and executive attention are minimized or eliminated after statistically taking into account the relationship between aging and processing speed (Salthouse 1996a; Verhaeghen and Salthouse 1997). Measures of processing speed have also been shown to correlate with neurobiological markers of aging (Eckert 2011). While this framework provides a powerful and parsimonious account for changes that occur as people grow older, one criticism is that it does not provide a straightforward account for the entire pattern of behaviors observed in the literature, particularly in areas in which age-related declines are not observed (e.g., Balota et al. 2000, see also McCabe et al. 2010).

\subsubsection{Inhibition and Cognitive Control}

Older adults have a well-documented deficit in the ability to inhibit irrelevant stimuli (Hasher and Zacks 1988), which has been demonstrated in memory tasks (Gazzaley et al. 2005), visual tasks such as the Stroop task (Bugg et al. 2007), and auditory tasks such as dichotic listening (Rogers et al. In press). In this last example, participants listened to simultaneously presented auditory streams of words, one stream to each ear, preceded by a visual arrow that indicated the ear to which participants should attend. At recognition participants were instructed only to endorse words presented in the stream indicated by the arrow. Performance between young and older adults was equivalent in all conditions except for when recognition probes were words from the unattended stream. In those cases older adults were more likely than the young adults to erroneously endorse those items, indicating a deficit in suppression of the unattended stream (Tun et al. 2002). This kind of deficit in selective attention suggests that older adults may actually encode more, not less, than young adults, including both relevant and irrelevant information (Weeks and Hasher 2017).

\subsubsection{Working memory capacity}

Another domain in which older adults have deficits is in working memory. In the model of Baddeley (1986), working memory contains both a verbal memory buffer (the phonological loop) and a visual memory buffer (the visuospatial sketchpad). These buffers allow for auditory and visual information respectively to be maintained for in an active state for a finite period of time. Baddeley's (1986) model also includes a central executive component which allows for manipulation and processing of information contained within these buffer and long-term memory systems in order to achieve goals of a specific task (Rudner and Ronnberg 2008). For example, retaining the digits of a phone number would be considered a task tapping short-term memory, 
whereas separating the digits into odd and even numbers then reciting them in ascending order would likely tap central executive processes (Belleville et al. 1998). The central executive component is considered to be the locus of age-related declines in working memory (Rose et al. 2009), specifically with regard to its role of suppression of task-irrelevant stimuli (Gazzaley et al. 2005). Indeed, a factor-analytic study performed by McCabe et al. (2010) revealed latent measures of working memory and executive function correlate at a level of 0.97 .

\subsubsection{Episodic Memory}

Episodic memory is defined as the capacity for memory for specific past events including details about where and when the event occurred (Tulving \& Szpunar, 2009), and allows for people to remember specific autobiographical information about their own lives. For example, whereas semantic memory allows one to know what kind of dinner is served at an Italian restaurant, episodic memory allows for one to remember the last time they ate Italian food, who they ate with, and how good the food was.

Episodic memory is generally considered to decline as a function of age (Craik 2008), probably due to age-related changes in a number of related cognitive processes. Memory is generally assumed to occur at three different stages: encoding (where events are initially store into memory), retention (where memories are held for a duration of time), and retrieval (when memories are accessed) (Melton 1963). Older adults have been shown to have declines in the ability to encode events into long-term memory (Craik and Rose 2012), with older adults less likely than young adults to engage in self-initiated elaborative encoding strategies that are beneficial for long-term retention (Craik and Rabinowitz 1985). When controlling for initial encoding, older and young adults are generally assumed to have similar rates of memory retention (Park et al. 1988). However, older adults also show deficits relative to young adults to retrieve memories when prompted (Craik and McDowd 1987). With regard to retrieval processes in particular, the largest evidence of age-related changes are observed at free recall, however, when older adults are given helpful cues to facilitate retrieval, differences between young and older adults are minimized (Smith 1977).

Executive attention deficits contribute to older adults' poorer episodic memory. For example, McCabe et al. (2010) demonstrated that statistically controlling for age-related declines in executive attention reduced or eliminated age differences in episodic memory.

\subsubsection{Metacognition}

One particularly interesting aspect of age-related cognitive change is the extent to which people have insight over their own cognitive states. For example, are listeners are aware of the extent their hearing or cognitive abilities? Nelson and Narens' (1990) seminal framework describes metacognition as two processes that operate between the object level (e.g., actual cognitive processing) and the meta level (e.g., awareness of this processing). The flow of information from the object level to the meta level is called monitoring, and the flow of information from the meta level to the object level is called control. For example, monitoring occurs when one notices that they are having a hard time hearing the television after the air conditioner kicks on, and control occurs when one increases the television volume in response to that awareness.

Hertzog and Dunlosky (2011) report that older adults' monitoring is preserved relative to young adults in episodic memory tasks, and that their predictions and post-dictions of future and past performance are well calibrated. However, this pattern of age invariance does not appear to hold when tasks require executive attention at the object level (Souchay and Isingrini 2004). For example, in a study by Kelley and Sahakyan (2003), young and older adults studied pairs of 
words (e.g., CLOCK - DOLLAR), and were tested using a cued recall test (e.g., CLOCK - DO_ - - R). The pair "CLOCK - DOLLAR" is an example of a control item in which pairs of words were not semantically associated. Kelley and Sahakyan (2003) also used deceptive items in which the words pairs were not semantically associated at study (e.g., NURSE - DOLLAR) but the cue fragment at test could erroneously lead to a semantic associate of the first word (e.g., NURSE - $\mathrm{DO}_{-}{ }_{-} \mathrm{R}$ ). Note that successful performance on these deceptive items requires inhibiting the semantic associate "DOCTOR" to respond correctly with the studied item DOLLAR. During each trial at test, participants made a cued recall attempt, then rated their confidence in their memory (e.g., monitoring), and then decided if they wanted their response to be scored for a later monetary incentive (e.g., control). The results of that study showed that while cued recall for control items was poorer for older adults than young adults overall, metacognitive judgments by older adults in terms of their confidence and willingness to have their responses scored were as well calibrated to their actual performance as young adults' metacognitive judgments. However, on deceptive items, where participants had to inhibit the semantic associate of the first word at recall, older adults' metacognitive judgments were poorly calibrated relative to young adults - older adults were more confident in their errors and more likely to volunteer to have their errors scored than were young adults. This study provides strong evidence that older adults have intact metacognition relative to young adults only to the extent that input to the monitoring process does not require executive attention.

\subsection{Resilience to Age-related Decline in Some Memory Systems Important for Speech Perception}

Despite widespread findings of age-related cognitive change in many areas, there are others in which older adults perform very similarly to young adults. Area of preserved performance in older adulthood are important because they may provide means for older adults to compensate for changes to hearing and cognition in service of speech understanding.

\subsubsection{Echoic Memory}

Echoic memory is short-term auditory store that holds sensory-based auditory information for a very short period of time, probably on the order of hundreds of milliseconds (see Cowan 1984 for a detailed consideration of the duration of the echoic store). For example, during a telephone conversation where the listener asks the speaker to repeat themselves, and yet remembers what the speaker initially said before the speaker even attempts to repeat, it is likely that the listener was able to retrieve the spoken information from echoic memory. As with its visual analogue, iconic memory (Sperling 1960), echoic memory has been shown to be invariant with age (Parkinson and Perey 1980), and it not considered to be a likely locus of age-related decrements to speech perception. The same age invariance has been found to be true with an electrophysiological correlate of echoic memory derived from the mismatch negativity (Näätänen et al. 2007) wave of event-related potentials (Alain and Woods 1999).

\subsubsection{Short-term Memory}

Short-term memory, also known as primary memory, is typically defined as the capacity to maintain small quantities of information in the focus of immediate awareness for a short period of time (Waugh and Norman 1965). For example, holding a telephone number in mind long enough to enter it into a phone is a task that requires short-term memory. This type of processing is reflected in tasks such as forward digit span, where participants listen to and repeat aloud a string of digits. While individual studies of age on forward digit span have revealed modest or no 
308

309

310

311

312

313

314

315

316

317

318

319

320

321

322

323

324

325

326

327

328

329

330

331

332

333

334

335

336

effects of age (Craik 1977), a meta-analysis by Verhaeghen et al. (1993) revealed that older adults do less well on forward digit spans tasks than young adults. However, some have argued that the observed age difference in forward digit span is more likely to reflect age differences in long-term memory and speaking articulation rate, which has been shown to be slower in older adults (Multhaup et al. 1996; Zacks et al. 2000).

\subsubsection{Repetition Priming}

Priming is defined as a nonconscious form of memory typically associated with the perceptual identification of stimuli (Tulving and Schacter 1990). Studies of repetition priming commonly involve initial exposure of a target stimulus, and after a delay period that could vary from seconds to years, a test exposure of the same stimulus, albeit under some form of degradation, obliteration, or compression. A common example from the auditory domain is auditory noise masking, where a word could be spoken clearly, and then in a later test phase of the experiment, presenting that same word with a significant degree of masking. Typically, older adults show similar repetition priming to young adults, although older adults with Alzheimer's Disease (AD) show impaired repetition priming (Fleischman and Gabrieli 1998).

\subsubsection{Semantic Priming}

In semantic priming, the accessibility of a target item can be changed by prior exposure to a different but conceptually-related stimulus. A common example of semantic priming is that of paired associates, where a word comes to mind more easily in the presence of a semanticallyrelated cue word (e.g., 'dog-cat' or 'ocean-water' the second word is more readily accessed than 'dog-water' or 'ocean-cat' because of the conceptual relationship of the pair). Studies of semantic priming have been used to understand how concept knowledge is organized. The most common form of semantic priming paradigm is when the relationship between the prime (e.g., 'dog') and the target (e.g., 'cat') is manipulated. Given 'dog' as a prime, participants are quicker identify the target word 'cat' than when given 'corn' as a prime (Neely 1977). To the extent that timing of these responses reflects the underlying semantic network, we can understand the spreading of activation from one lexical entry to another, and the relative integrity of the semantic system. Typically, older adults report equal or stronger semantic priming effects to that of young adults (Burke et al. 1987; Laver and Burke 1993).

\section{Behavioral and Pupillometric Evidence for Interactions Between Hearing and Cognition}

This section reviews studies that have highlighted the interactivity of different sensory and cognitive systems that operate in the service of speech perception and language understanding. While age-related declines to hearing loss and cognition are often studied independently, there is an increasing trend for researchers to study the interactions between hearing loss and cognitive decline as a way to understand the underlying basis for language. For example, to investigate the question, "How does attention enhance auditory perception?" it may be helpful to study aging populations that are known to have declines in attentional control. Likewise, researchers interested in the impacts of hearing on attention may study populations with hearing loss as a way of understanding the input to attentional control systems. 


\subsection{Episodic Memory}

Rabbitt (1968) performed a study that showed a remarkable dissociation between identification and memory for spoken words. In this study, participants listened to and repeated spoken digits with a variable signal-to-noise ratio (SNR). The words in this study were arranged in lists such that after hearing a certain number of words, participants would hear a tone and then have to correctly recall the words they had just identified (i.e., free recall). The SNRs in this study were carefully chosen so as to have little effect on identification. Indeed, the manipulation of SNR had little effect on identification rates. However, free recall was significantly worsened at less favorable SNRs. Rabbitt proposed that the effort used to identify words at less favorable SNRs prevented sufficient rehearsal and encoding of the words into long-term memory, and thereby negatively impacted free recall. This mechanism was later confirmed in a study by Piquado et al. (2010b), who found that that acoustic degradation of a single word disrupts memory for not only the degraded word, but also the word presented immediately prior to it.

Nearly 25 years later after his original experiment, Rabbit (1991) performed a similar experiment with older adults, and, rather than manipulating the SNR within-subjects, compared groups of older adults with and without hearing loss, and found that those with hearing loss showed poorer free recall than those with good hearing for their age, even when both groups had displayed perfect identification accuracy. Suprenant (2007) found a very similar pattern when manipulating SNR within-subjects for older and young adults, and found that even small levels of auditory degradation that do not show changes in identification accuracy can prove significantly deleterious for free recall.

Koeritzer et al. (In press) presented young and older listeners with lists of spoken sentences in different levels of background noise (multitalker babble). The sentences varied in their linguistic challenge, with half containing one or more ambiguous words ("bark" could refer to the sound a dog makes, or the outer covering of a tree). These high-ambiguity sentences have been shown to rely on domain-general cognitive resources (Rodd et al. 2010, 2012) and may thus potentially interact with acoustic challenge drawing on these same resources. Following a list of sentences, listeners were visually presented with a list of sentences that contained sentences they had heard, and foils that were not heard. Listeners were asked to perform a recognition memory judgment task, indicating for each sentence whether the item had been heard ("old") or not ("new"). The authors found that recognition memory was poorer for high-ambiguity sentences, poorer for sentences in more challenging SNRs, and that the two factors interacted to challenge memory. Perhaps most telling, for the older adults tested, pure-tone hearing sensitivity and measures of verbal working memory both significantly correlated with memory performance in the most challenging condition.

They key takeaway from these studies is that breakdowns in the sensory processing system, either via hearing loss or acoustic degradation of the stimulus, have a cascading impact upon the cognitive systems required for understanding spoken language (Gordon-Salant and Fitzgibbons 1997). Participants with hearing loss report that certain noisy environments require more effort or concentration while listening (Xia et al. 2015). Immediate perceptual identification of the stimulus may not be impacted, but the additional demand on cognitive processing disrupts important functions of the cognitive system for language understanding such as encoding information into long-term memory or performance on a secondary task (Gagne et al. 2017). 


\subsection{Pupillometric Measures}

An exciting development in the understanding of the cognitive demands placed on listeners in difficult auditory environments arises from studies using pupillometry, which relies on measuring pupil size as an index of cognitive effort. Pupillometry is exciting because it provides an online physiological measure of demands incurred while listening. Fluctuations in pupil size are known to happen as a result of light adaptation, but have also been thought to reflect changes in task demands from attention and memory (Kahneman 1973). In a study of middle-aged adults with normal hearing or impaired hearing for their age, Zekveld et al. (2011) found less of a change in pupil dilation when moving from easy to difficult levels of background masking, replicating a prior study conducted with a sample of young adults (Zekveld et al. 2010). In both studies the authors argued this change in pupil dilation reflected a diminished release of effort when in less adverse listening conditions. Such release of effort is anticipated in participants when moving from difficult to less difficult listening conditions, and has also been observed when participants give up on a difficult listening task (Zekveld and Kramer 2014).

Kuchinsky et al. (2012) tested older adults' ability to identify words in background noise and found that pupil size increased as SNR became more difficult. Pupil size was also found to increase as a function of the number of phonological competitors of the target word, indicating that participants were experiencing more cognitive demand as a result of lexical competition. Piquado et al. (2010a) found that linguistic variables such as sentence length and syntactic complexity impact pupil dilation in a task testing memory for spoken sentences. Interestingly, while Piquado et al. tested both young and older adults, only young adults revealed an effect of syntactic complexity on pupil dilation. Piquado et al. concluded this finding indicated that older adults were likely processing the syntactic complexity of the sentences to a poorer extent than the young adults, and as evidence for a "good enough" approach to listening in older adults (Amichetti et al. 2016).

\subsection{The Modulatory Effects of Context}

Additional cognitive demands incurred while listening to degraded speech can, in part, be mitigated by supportive linguistic and semantic context as frequently occurs in natural speech. McCoy et al. (2005) used a free recall approach similar to that of Rabbitt (1991), and found that hearing-impaired older adults did not have impaired free recall relative to older adults with good hearing when the words shared a semantic context. One reason this may happen is because supportive context may reduce the need for bottom-up sensory fidelity. To this point, Sheldon et al. (2008) found that older and young adults' perceptual thresholds for words were improved when preceded by facilitative priming, sentential context, or a combination of both.

The findings of McCoy et al. (2005) and Sheldon et al. (2008) complement a wider literature that has shown that older adults greatly benefit from the addition of facilitative linguistic and semantic context as a way to compensate for age-related hearing loss (PichoraFuller 2008). In this sense context provides a basis for expectation, and reduces the amount of bottom-up acoustic information needed to achieve successful identification of a stimulus. For example, in a study using a word-onset gating methodology (Grosjean 1980) where listeners were given incrementing $50 \mathrm{~ms}$ segments of target words until recognition was achieved, Lash et al. (2013) found that listeners required fewer segments when identifying words preceded by strongly constraining sentences (e.g., "He mailed the letter without a STAMP") compared to weakly constraining sentences (e.g., "He did not say anything about the STAMP"). Lash et al. also found that this benefit of context was larger for older adults with and without hearing loss 
436

437

438

439

440

441

442

443

444

445

446

447

448

449

450

451

452

453

454

455

456

457

458

459

460

461

462

463

464

465

466

467

468

469

470

471

472 when compared to young adults. An initial explanation for older adults' use of context was provided by Sommers \& Danielson (1999), who held that semantic and linguistic context improved word identification by reducing the set of potential competitors in the lexicon, reducing the requirement for inhibition of phonological competitors (especially useful for older adults, who have a well-documented inhibition deficit), and thereby facilitating lexical discrimination.

In light of age-related declines to hearing and cognitive abilities, it is remarkable that language understanding among the elderly is as high as it is (Wingfield and Stine-Morrow 2000). This feat may be evidence that multiple systems responsible for language understanding interact to cover for age-related declines. For example, crystallized language knowledge such as vocabulary increases with age (Park et al. 1996), and may be indicative of certain linguistic skills that acquired over the developmental lifespan could compensate for age-related hearing loss (Pichora-Fuller 2008; Benichov et al. 2012). This type of language expertise could be of the kind that allows for older adults to use context to compensate for age-related hearing loss. However, it is unclear to what extent that context actually improves older adults' ability to hear language. To assess this further, Rogers et al. (2012) measured young and older adults' word identification for masked target words preceded by clearly presented primes that created facilitative semantic context (e.g., "row-BOAT"), misleading semantic context (e.g., "row-GOAT"), and neutral context conditions (e.g., "cloud-BOAT"). The authors found that older adults had better performance than young adults on facilitative context conditions, but were more likely than young adults to falsely hear the word predicted by the misleading semantic context (e.g., reporting "BOAT" when given "row-GOAT"). This pattern was also reflected in the pattern of young and older adults' metacognitive monitoring (i.e. confidence in their responses), where older adults were much more confident in making responses that matched the semantic context, even when their responses were incorrect in the case of the misleading semantic context. Such a pattern indicates that context use by older adults does not improve hearing per se, but rather provides a basis for older adults to respond that could be helpful or misleading. In the real world, where context is much more likely to be helpful than misleading, this could be of real benefit, particularly in the case of the kinds of conditions reported by McCoy et al. (2005), where context can reduce demands on the cognitive system. However, older adults' confidence in their responses indicates that this happens without their awareness, and may not be aware of when context is misleading (Rogers and Wingfield 2015; Rogers 2016). Exactly because this reflexive use of context may be useful in the world, it may reflect a "good-enough" linguistic processing strategy, where older adults have learned that the potential drawbacks resulting from misleading utterances is not worth the effort needed to detect them. This kind of strategy has been shown in older adults' processing of textual garden-path sentences in reading (Ferreira et al. 2002; Christianson et al. 2006).

\section{Neuroimaging Evidence for Interactions Between Hearing and Cognition}

Complementing evidence from behavior and pupillometry is a growing literature of neuroimaging studies that speaks to cognitive processes required to make sense of degraded speech. Only a small number of neuroimaging studies directly examine how hearing loss affects patterns of brain activity, but studies examining responses to a variety acoustic challenges in listeners with good hearing help provide some context for the types of brain recruitment that might be expected. 


\title{
5.1 Neuroanatomical Frameworks for Spoken Word and Sentence Comprehension
}

\author{
Before considering how aging and hearing loss might affect the brain networks used to
} understand speech, it is first useful to consider what a "core" language processing network in the brain looks like in the absence of these additional challenges. Fortunately, many decades of research on language processing in patients with brain damage, complemented by functional brain imaging in healthy listeners, have provided a relatively clear picture on what this network might look like.

Acoustic information first reaches the brain bilaterally in primary auditory cortex, and speech perception pathways flow from this initial point. As a general rule, "lower-level" speech features are processed bilaterally and in regions that are anatomically neighboring auditory cortex. Phoneme processing, for example, differentially modulates posterior superior temporal sulcus (STS) (Liebenthal et al. 2005), and single-word comprehension further activates regions of middle temporal gyrus bilaterally (Binder et al.2000). Evidence for word processing being supported by both left and right hemisphere comes from the fact that listeners who have had their left or right hemisphere anesthetized using a Wada procedure are still able to understand words (Hickok et al. 2008).

As the linguistic demands of speech become more complex, additional brain regions are engaged. For example, combinatorial processes that integrate information across multiple words ("plaid jacket" or "red boat" vs. "jacket" or "boat") engage the angular gyrus (Price et al. 2015; Price et al. 2016) and anterior temporal lobe (Bemis and Pylkkanen 2013; Ziegler and Pylkkanen 2016). The brain networks active during sentence comprehension frequently involve left anterior temporal lobe (Evans et al. 2014) and left inferior frontal gyrus (IFG) (Rodd et al. 2005; Davis et al. 2011), regions that show additional increases when syntactic demands are increased (Peelle et al. 2010b). Thus, regions for speech processing radiate from auditory cortex along dorsal and ventral streams that process increasingly complex aspects of the speech signal (Hickok and Poeppel 2007; Peelle et al. 2010a), and the degree of lateralization depends (at the very least) on the level of linguistic processing required (Peelle 2012).

\subsection{Executive Attention Networks Respond to Errors in Speech Recognition: The Cingulo- opercular Network}

One of the most repeated findings in neuroimaging studies of speech comprehension is elevated activity in the cingulo-opercular network when speech is acoustically challenging enough to result in word recognition errors. The cingulo-opercular network is an executive attention network comprised of the anterior cingulate and bilateral frontal opercula (or perhaps the nearby anterior insulae). These regions can be thought of as a functional network because of their frequent co-activation during various cognitive tasks, and because of the strong correlation of their timecourses during rest (Dosenbach et al. 2008; Power and Petersen 2013). The anatomical location of the cingulo-opercular network and its involvement in speech tasks is shown in Fig. 3.

The timecourse of cingulo-opercular activity can provide some indication of its function during cognitive tasks (Neta et al. 2015). Relative to rest, the cingulo-opercular network shows increased activation at the beginning of a task block. However, it showed further punctate increases following errors. Thus, although it appears to have a role in error-monitoring, its function seems better defined as broadly concerned with task engagement, which is needed at the outset of a task, and needs to be revisited following errors.

Activity in the cingulo-opercular network is seldom seen when listeners process unchallenging speech (e.g., speech in quiet). However, when speech is acoustically challenging 
enough that listeners make mistakes in comprehension or word recognition, the cinguloopercular network is often engaged (Eckert et al. 2009). Cingulo-opercular activity has been seen in young adults with good hearing listening to noise-vocoded speech (Wild et al. 2012; Erb et al. 2013), older adults listening to noise-vocoded sentences (Erb and Obleser 2013), and older adults listening to single words in noise (Vaden Jr. et al. 2016).

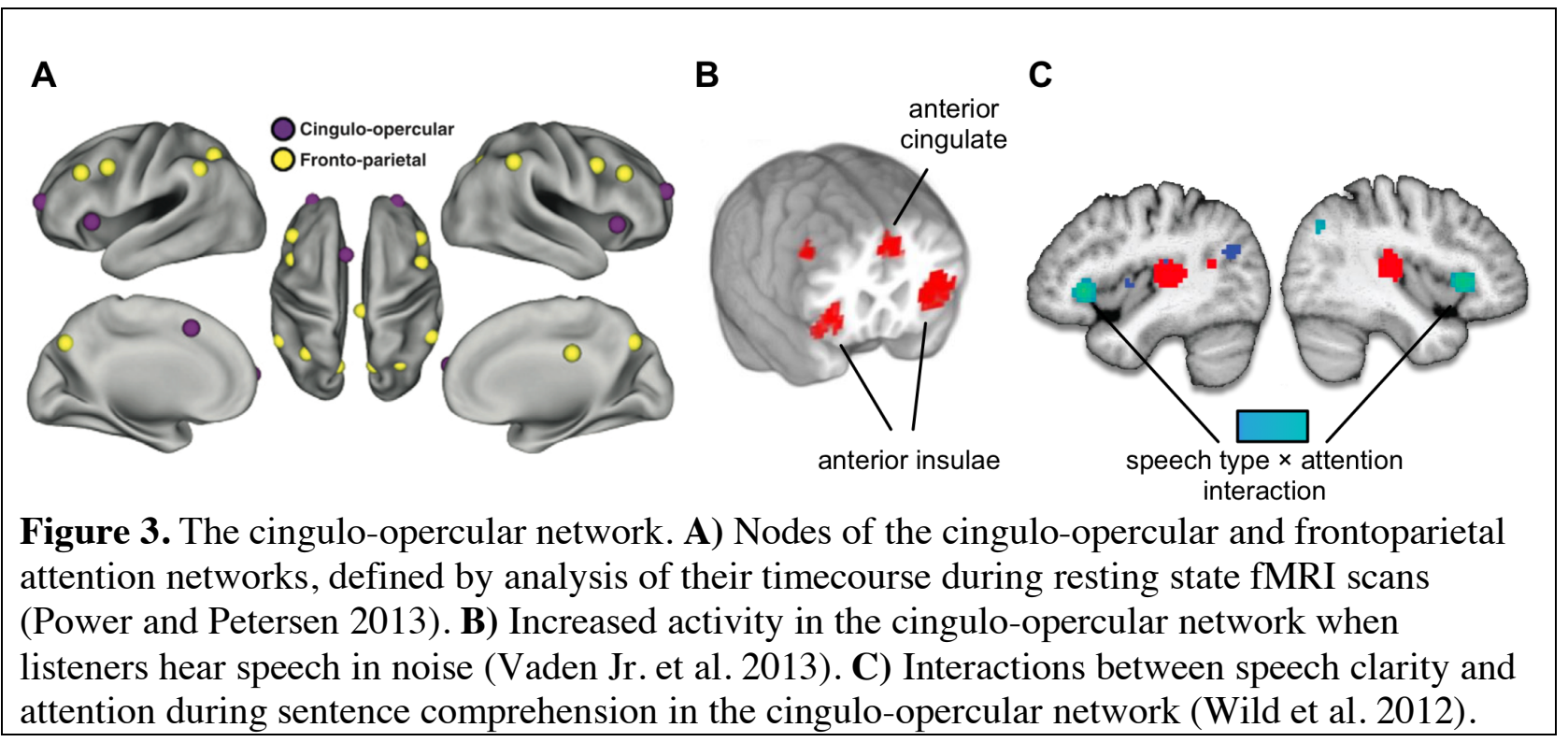

A particularly informative study in this context was conducted by Vaden and colleagues (2013). They conducted an fMRI study of word perception, with single words presented in background noise at an SNR difficult enough that participants made errors in word recognition. As in prior studies, Vaden et al. found elevated activity in the cingulo-opercular network following these error trials. However, they went one step further and conducted a general linear mixed model (GLMM) analysis to see whether this elevated activity was related to accuracy on the following trial. In other words, was cingulo-opercular activity "merely" a response to an error, or did it actually relate to participants' future performance? Their analysis showed that increased activity in the cingulo-opercular network following a word recognition error was indeed correlated with improved accuracy on the next trial. This finding is consistent with a role for the cingulo-opercular network in task engagement, and suggests that following an error participants were able to re-engage with the task (and thus perform more accurately) in proportion to activity in their cingulo-opercular network. Although initially demonstrated in young adults, this finding has also been shown in older adults with age-related hearing loss (Vaden Jr. et al. 2015).

Activity in the cingulo-opercular network also relates to which words are remembered on a subsequent memory test. Vaden and colleagues (2017) conducted an fMRI study in which they played words embedded in background noise for young adult listeners with good hearing. Following the listening portion, listeners completed a recognition memory test on the presented words. They found that memory encoding in difficult listening conditions was poorer when cingulo-opercular activity was not sustained, suggesting a role for this network not only in perception but in post-perceptual tasks (such as remembering what has been heard). 
554

\subsection{Responses in Prefrontal Cortex and the Successful Perception of Acoustically- challenging Speech}

Although there is converging evidence regarding the role of the cingulo-opercular network when listeners make recognition errors, there is less agreement on what other neural and cognitive systems might be involved in supporting successful comprehension. Some additional anatomical evidence comes from studies showing increased activity in regions of prefrontal and premotor cortex when speech is acoustically challenging.

Davis and Johnsrude (2003) presented listeners with spoken sentences that parametrically varied in intelligibility as a result of three different acoustic manipulations: noise vocoding, background noise, or temporal interruption. Varying intelligibility in similar ways but using different signal processing approaches allowed the authors to examine whether responses to changes in intelligibility depended on the specific acoustic form of the signal. For speech that was acoustically degraded, the authors found a large swath of increased activity in left prefrontal cortex. This activity did not depend on the acoustic manipulation used, suggesting it reflects a higher-level response to a decrease of intelligibility.

Although activity in prefrontal cortex is frequently seen when speech is acoustically challenging, there is still debate about what role this activity may be playing in perception. Some of these regions appear to overlap with portions of the frontoparietal attention network (Power and Petersen 2013), part of a set of regions that respond to a variety of general task demands (Duncan 2010; Jackson et al. 2017).

During acoustically challenging listening situations, activity is also seen in premotor cortex. This observation has led to the suggestion that motor representations may be engaged during speech perception (Watkins et al. 2003; Skipper et al. 2005). That is, when the acoustic signal is unclear, listeners may engage their own motor speech representations to help make sense of the degraded signal. However, it is important to note that the role of motor representations in speech perception is far from clear (Lotto et al. 2009). Outstanding questions remain regarding whether motor activity is obligatory or necessary during speech perception, and the degree to which its role may be influenced by the acoustic clarity of the signal (for example, whether motor representations may be relied upon differently in quiet compared to in the presence of background noise).

\section{A Framework for Considering Auditory and Cognitive Interactions in Speech Perception}

Although the chapter has focused on auditory and cognitive interactions in listeners with agerelated hearing loss, it has also emerged that principles learned from studying this group should generalize to other populations. This section presents a general framework for thinking about auditory-cognitive interactions during speech perception.

The framework, shown in Fig. 4A, focuses on speech perception at the level of the individual listener. In a given listening situation, the cognitive demand placed on a listener depends, minimally, on both the acoustic and linguistic challenge of the speech signal. The acoustic challenge reflects contributions of the listener (e.g., hearing sensitivity), the speech signal (e.g., clarity of articulation), and the environment (e.g., background noise) (Denes and Pinson 1993). The linguistic challenge reflects innate demands of speech processing (single words vs. sentences). For a given level of cognitive demand, the cognitive resources actually engaged by a listener depend on the available resources (e.g., a listener's verbal working 
A
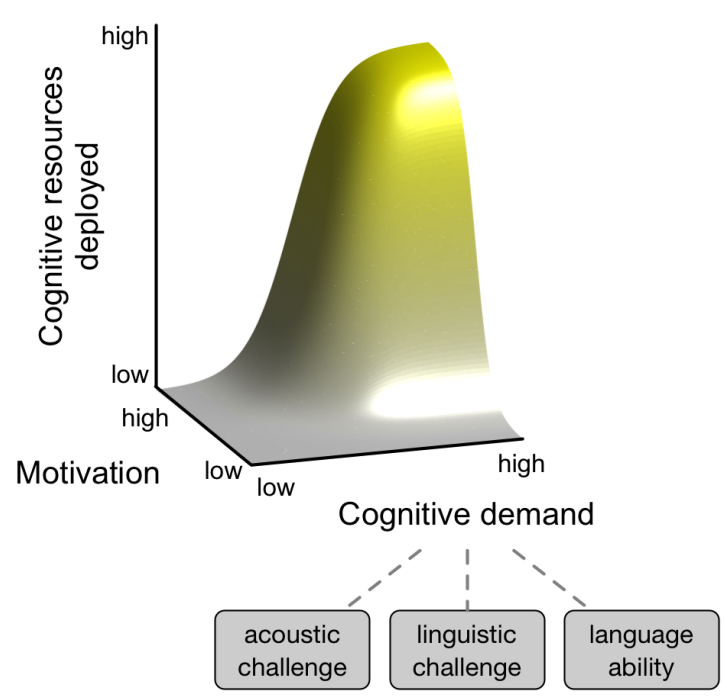

B

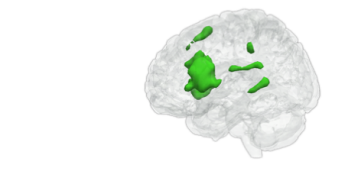

Listener 1

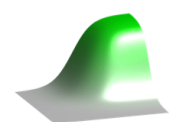

Listener 2

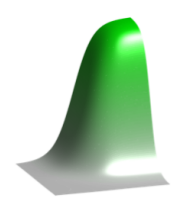

Listener 3

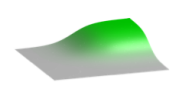

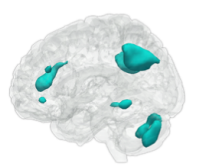
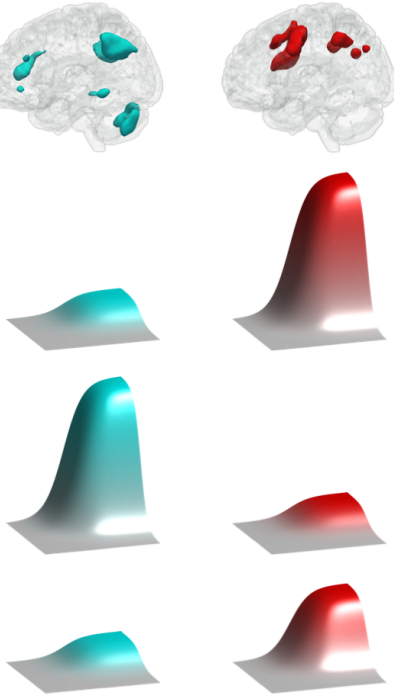

Figure 4. Framework for cognitive resource allocation during speech understanding. A) The cognitive resources engaged during speech understanding vary as a function of the cognitive demands of the task and a listener's motivation to understand what is being said. B) Rather than monolithic "cognitive resources", different listeners may engage dissociable brain networks to various degrees in order to understand what they are hearing.

602

603

604

605

606

607

608

609

610

611

612

613

614

615

616

617

618

619

An important aspect of this framework, illustrated in Fig. 4B, is that cognitive resources are not monolithic. That is, although it is a convenient shorthand, speaking of a listener increasing "cognitive resources" grossly oversimplifies what listeners actually do (Wingfield 2016). Rather, each listener has a number of dissociable brain networks that support various cognitive function, each with a biologically-constrained capacity. These various networks can thus be engaged to differing degrees in a particular listening situation.

Another critical point, not necessarily obvious from Fig. 4, is that different listeners might achieve a similar level of performance through different patterns of neural engagement. That is, when listening to a talker in a noisy restaurant (causing cognitive demand), one listener may increase activity in the cingulo-opercular network whereas a second listener may increase activity in prefrontal cortex. One would expect this based in part on electrophysiological studies in other animals that suggest multiple combinations of neural activity can result in identical behavior (Prinz et al. 2004; Gutierrez et al. 2013). Thus, even when performance is equated across listeners (including when performance is essentially perfect), listeners may be engaging in different neural "strategies" to achieve this level of performance.

How might this framework be applied in the context of a group of young adults, all of whom have clinically normal hearing? One would expect that by measuring their hearing ability 
620

621

622

623

624

and cognitive ability it would be possible to predict the degree to which they would need to recruit cognitive resources in order to understand speech, assuming they were motivated to do so. And, in fact, if an individual's cognitive ability were lower than the demand, one would expect performance to suffer (for example, speech might become less intelligible compared to its intelligibility for listeners with greater cognitive ability).

\section{Chapter Summary}

Understanding spoken language relies not only on the auditory system, but on linguistic and cognitive processing that acts on the acoustic signal. Individual differences in any of these abilities can affect a listener's success at understanding speech, and the cognitive and neural systems required to achieve this level of success. Because adult aging is associated with changes in both hearing and cognition, it provides an informative window into how these domains interact in all listeners.

One clear area for future growth is that of individual difference analyses, which are important for both theoretical and clinical reasons. Theoretically, contemporary theories (such as the framework outlined in the previous section) predict that individual differences in the amount of auditory challenge will relate to cognitive demand in individual listeners. Thus, accurate estimates of ability and challenge for an individual listener are required to test this prediction. From a clinical perspective, it is necessary to make judgments about the difficulties and interventions at the level of individual listeners, and thus accurate estimates are required without pooling data across a group. In this context it will also be critical to ensure that any measures of brain structure or function are reliable at the individual level, which may require more data per individual than is typically collected for group studies (Gordon et al. 2017).

A second area where there is ample room for improvement is moving towards the use of more sophisticated measures of hearing and cognitive ability in the context of brain and cognitive measures. Many of the published studies - particularly fMRI studies-have relied heavily on pure tone averages as a summary measure of hearing ability. Expanding measures of hearing ability to include multiple frequencies, measure of "hidden" hearing loss, temporal processing, and auditory filter bandwidth is likely to prove more useful in estimating the auditory challenge faced by individual listeners. Similarly, age-related cognitive decline is a multifaceted concept, and will similarly benefit from more complex measurement approaches. Finally, these increased amounts of data will need more complex theories to constrain their interpretation. These theories need to reflect a more sophisticated understanding of what the cognitive processes are in speech perception and how accurately these can be assessed, so that the conditions under which they are engaged can be determined.

\section{Acknowledgements}

This work was supported by grants R01DC014281, R21DC015884, and R56AG018029 from the US National Institutes of Health. 


\section{Compliance with Ethics Requirements}

658 Jonathan Peelle declares no conflicts of interest.

659 Chad Rogers declares no conflicts of interest. 
661

662

663

664

665

666

667

668

669

670

671

672

673

674

675

676

677

678

679

680

681

682

683

684

685

686

687

688

689

690

691

692

693

694

695

696

697

698

699

700

701

702

703

Alain, C., \& Woods, D. L. (1999). Age-related changes in processing auditory stimuli during visual attention: evidence for deficits in inhibitory control and sensory memory. Psychology and Aging, 14(3), 507-519.

Alain, C., Roye, A., \& Salloum, C. (2014). Effects of age-related hearing loss and background noise on neuromagnetic activity from auditory cortex. Frontiers in Systems Neuroscience, 8,8 .

Amichetti, N. M., White, A. G., \& Wingfield, A. (2016). Multiple Solutions to the Same Problem: Utilization of Plausibility and Syntax in Sentence Comprehension by Older Adults with Impaired Hearing. Frontiers in Psychology, 7, 789.

Anderson, S., Parbery-Clark, A., White-Schwoch, T., \& Kraus, N. (2012). Aging affects neural precision of speech encoding. Journal of Neuroscience, 32(41), 14156-14164.

Anderson, S., Parbery-Clark, A., White-Schwoch, T., Drehobl, S., \& Kraus, N. (2013). Effects of hearing loss on the subcortical representation of speech cues. Journal of the Acoustical Society of America, 133(5), 3030-3038.

Baddeley, A. D. (1986). Working Memory. Oxford: Clarendon Press.

Balota, D. A., Dolan, P. O., \& Duchek, J. M. (2000). Memory changes in healthy older adults The Oxford handbook of memory. (pp. 395-409). New York, NY, US: Oxford University Press.

Bao, J., \& Ohlemiller, K. K. (2010). Age-related loss of spiral ganglion neurons. Hearing Research, 264, 93-97.

Belleville, S., Rouleau, N., \& Caza, N. (1998). Effect of normal aging on the manipulation of information in working memory. Memory and Cognition, 26(3), 572-583.

Bemis, D. K., \& Pylkkanen, L. (2013). Basic linguistic composition recruits the left anterior temporal lobe and left angular gyrus during both listening and reading. Cerebral Cortex, 23(8), 1859-1873.

Benichov, J., Cox, L. C., Tun, P. A., \& Wingfield, A. (2012). Word recognition within a linguistic context: Effects of age, hearing acuity, verbal ability and cognitive function. Ear and Hearing, 32, 250-256.

Bharadwaj, H. M., Masud, S., Mehraei, G., Verhulst, S., \& Shinn-Cunningham, B. G. (2015). Individual differences reveal correlates of hidden hearing deficits. Journal of Neuroscience, 35, 2161-2172.

Bilger, R. C., \& Wang, M. D. (1976). Consonant confusions in patients with sensorineural hearing loss. Journal of Speech and Hearing Research, 19(4), 718-748.

Binder, J. R., Frost, J. A., Hammeke, T. A., Bellgowan, P. S., Springer, J. A., Kaufman, J. N., \& Possing, E. T. (2000). Human temporal lobe activation by speech and nonspeech sounds. Cerebral Cortex, 10(5), 512-528.

Braver, T. S., \& Barch, D. M. (2002). A theory of cognitive control, aging cognition, and neuromodulation. Neuroscience and Biobehavioral Reviews, 26(7), 809-817.

Bugg, J. M., DeLosh, E. L., Davalos, D. B., \& Davis, H. P. (2007). Age differences in Stroop interference: contributions of general slowing and task-specific deficits. Aging, Neuropsychology, and Cognition, 14(2), 155-167.

Burianova, J., Ouda, L., Profant, O., \& Syka, J. (2009). Age-related changes in GAD levels in the central auditory system of the rat. Experimental Gerontology, 44, 161-169. 
704
Burke, D. M., White, H., \& Diaz, D. L. (1987). Semantic priming in young and older adults: evidence for age constancy in automatic and attentional processes. Journal of Experimental Psychology: Human Perception and Performance, 13(1), 79-88.

Caspary, D. M., Ling, L., Turner, J. G., \& Hughes, L. F. (2008). Inhibitory neurotransmission, plasticity and aging in the mammalian central auditory system. Journal of Experimental Biology, 211, 1781-1791.

Cerella, J. (1985). Information processing rates in the elderly. Psychological Bulletin, 98(1), 6783.

Christianson, K., Williams, C. C., Zacks, R. T., \& Ferreira, F. (2006). Younger and Older Adults' "Good-Enough" Interpretations of Garden-Path Sentences. Discourse Process, 42(2), 205-238.

Cowan, N. (1984). On short and long auditory stores. Psychological Bulletin, 96(2), 341-370.

Craik, F. I. (2008). Memory changes in normal and pathological aging. Canadian Journal of Psychiatry, 53(6), 343-345.

Craik, F. I., \& Rabinowitz, J. C. (1985). The effects of presentation rate and encoding task on age-related memory deficits. Journal of Gerontology, 40(3), 309-315.

Craik, F. I., \& Rose, N. S. (2012). Memory encoding and aging: a neurocognitive perspective. Neuroscience and Biobehavioral Reviews, 36(7), 1729-1739.

Craik, F. I. M. (1977). Age differences in human memory. In J. E. Birren \& K. W. Schaie (Eds.), Handbook of the psychology of aging (pp. 384-420). New York: Van Nostrand Reinhold.

Craik, F. I. M., \& McDowd, J. M. (1987). Age differences in recall and recognition. Journal of Experimental Psychology: Learning, Memory, and Cognition, 13, 474-479.

Cruickshanks, K. J., Wiley, T. L., Tweed, T. S., Klein, B. E., Klein, R., Mares-Perlman, J. A., \& Nondahl, D. M. (1998). Prevalence of hearing loss in older adults in Beaver Dam, Wisconsin: The epidemiology of hearing loss study. American Journal of Epidemiology, $148,879-886$.

Davis, M. H., \& Johnsrude, I. S. (2003). Hierarchical processing in spoken language comprehension. Journal of Neuroscience, 23(8), 3423-3431.

Davis, M. H., Ford, M. A., Kherif, F., \& Johnsrude, I. S. (2011). Does semantic context benefit speech understanding through "top-down" processes? Evidence from time-resolved sparse fMRI. Journal of Cognitive Neuroscience, 23, 3914-3932.

de Villers-Sidani, E., Alzghoul, L., Zhou, X., Simpson, K. L., Lin, R. C. S., \& Merzenich, M. M. (2010). Recovery of functional and structural age-related changes in the rat primary auditory cortex with operant training. Proceedings of the National Academy of Science, 107, 13900-13905.

del Campo, H. N. M., Measor, K. R., \& Razak, K. A. (2012). Parvalbumin immunoreactivity in the auditory cortex of a mouse model of presbycusis. Hearing Research, 294, 31-39.

Denes, P. B., \& Pinson, E. N. (1993). The Speech Chain: The physics and biology of spoken language. Long Grove, IL: Waveland Press, Inc.

Dosenbach, N. U. F., Fair, D. A., Cohen, A. L., Schlaggar, B. L., \& Petersen, S. E. (2008). A dual-networks architecture of top-down control. Trends in Cognitive Sciences, 12, 99105.

Duncan, J. (2010). The multiple-demand (MD) system of the primate brain: mental programs for intelligent behaviour. Trends in Cognitive Sciences, 14, 172-179.

Eckert, M. A. (2011). Slowing down: age-related neurobiological predictors of processing speed. Frontiers in Neuroscience, 5, 25. 
Eckert, M. A., Cute, S. L., Vaden Jr., K. I., Kuchinsky, S. E., \& Dubno, J. R. (2012). Auditory cortex signs of age-related hearing loss. Journal of the Association for Research in Otolaryngology, 13, 703-713.

Eckert, M. A., Menon, V., Walczak, A., Ahlstrom, J., Denslow, S., Horwitz, A., \& Dubno, J. R. (2009). At the heart of the ventral attention system: The right anterior insula. Human Brain Mapping, 30, 2530-2541.

Engle, J. R., Gray, D. T., Turner, H., Udell, J. B., \& Recanzone, G. H. (2014). Age-related neurochemical changes in the rhesus macaque inferior colliculus. Frontiers in Aging Neuroscience, 6, 73.

Erb, J., \& Obleser, J. (2013). Upregulation of cognitive control networks in older adults' speech comprehension. Frontiers in Systems Neuroscience, 7, 116.

Erb, J., Henry, M. J., Eisner, F., \& Obleser, J. (2013). The brain dynamics of rapid perceptual adaptation to adverse listening conditions. Journal of Neuroscience, 33, 10688-10697.

Evans, S., Kyong, J. S., Rosen, S., Golestani, N., Warren, J. E., McGettigan, C., MourãoMiranda, J., Wise, R. J. S., \& Scott, S. K. (2014). The pathways for intelligible speech: Multivariate and univariate perspectives. Cerebral Cortex, 24, 2350-2361.

Ferreira, F., Bailey, K. G. D., \& Ferraro, V. (2002). Good-enough representations in language comprehension. Current Directions in Psychological Science, 11, 11-15.

Fleischman, D. A., \& Gabrieli, J. D. (1998). Repetition priming in normal aging and Alzheimer's disease: a review of findings and theories. Psychology and Aging, 13(1), 88-119.

Gagne, J. P., Besser, J., \& Lemke, U. (2017). Behavioral Assessment of Listening Effort Using a Dual-Task Paradigm. Trends in Hearing, 21, 1-25.

Gao, F., Wang, G., Ma, W., Ren, F., Li, M., Dong, Y., Liu, C., Liu, B., Bai, X., Zhao, B., \& Edden, R. A. E. (2015). Decreased auditory GABA+ concentrations in presbycusis demonstrated by edited magnetic resonance spectroscopy. NeuroImage, 106, 311-316.

Gazzaley, A., Cooney, J. W., Rissman, J., \& D'Esposito, M. (2005). Top-down suppression deficit underlies working memory impairment in normal aging. Nature Neuroscience, 8 , 1298-1300.

Goman, A. M., \& Lin, F. R. (2016). Prevalence of Hearing Loss by Severity in the United States. American Journal of Public Health, 106(10), 1820-1822.

Gordon, E. M., Laumann, T. O., Gilmore, A. W., Newbold, D. J., Greene, D. J., Berg, J. J., Ortega, M., Hoyt-Drazen, C., Gratton, C., Sun, H., Hampton, J. M., Coalson, R. S., Nguyen, A. L., McDermott, K. B., Shimony, J. S., Snyder, A. Z., Schlaggar, B. L., Petersen, S. E., Nelson, S. M., \& Dosenbach, N. U. F. (2017). Precision Functional Mapping of Individual Human Brains. Neuron, 95(4), 791-807 e797.

Gordon-Salant, S., \& Fitzgibbons, P. J. (1997). Selected cognitive factors and speech recognition performance among young and elderly listeners. Journal of Speech, Language, and Hearing Research, 40(2), 423-431.

Grosjean, F. (1980). Spoken word recognition processes and the gating paradigm. Perception and Psychophysics, 28, 267-283.

Gutierrez, G. J., O'Leary, T., \& Marder, E. (2013). Multiple mechanisms switch an electrically coupled, synaptically inhibited neuron between competing rhythmic oscillators. Neuron, $77,845-858$.

Hasher, L., \& Zacks, R. T. (1988). Working memory, comprehension, and aging: A review and a new view. In G. A. Bower (Ed.), The psychology of learning and motivation: Advances in research and theory (Vol. 22, pp. 193-225). San Diego: Academic Press. 
Henry, K. S., Kale, S., \& Heinz, M. G. (2014). Noise-induced hearing loss increases the temporal precision of complex envelope coding by auditory-nerve fibers. Frontiers in Systems Neuroscience, 8, 20.

Herrmann, B., Henry, M. J., Johnsrude, I. S., \& Obleser, J. (2016). Altered temporal dynamics of neural adaptation in the aging human auditory cortex. Neurobiology of Aging, 45, 10-22.

Hertzog, C., \& Dunlosky, J. (2011). Metacognition in Later Adulthood: Spared Monitoring Can Benefit Older Adults' Self-regulation. Current Directions in Psychological Science, 20(3), 167-173.

Hickok, G., \& Poeppel, D. (2007). The cortical organization of speech processing. Nature Reviews Neuroscience, 8, 393-402.

Hickok, G., Okada, K., Barr, W., Pa, J., Rogalsky, C., Donnelly, K., Barde, L., \& Grant, A. (2008). Bilateral capacity for speech sound processing in auditory comprehension: Evidence from Wada procedures. Brain and Language, 107, 179-184.

Hughes, L. F., Turner, J. G., Parrish, J. L., \& Caspary, D. M. (2010). Processing of broadband stimuli across A1 layers in young and aged rats. Hearing Research, 264, 79-85.

Humes, L. E., Kidd, G. R., \& Lentz, J. J. (2013). Auditory and cognitive factors underlying individual differences in aided speech-understanding among older adults. Frontiers in Systems Neuroscience, 7, 55.

Jackson, J., Rich, A. N., Williams, M. A., \& Woolgar, A. (2017). Feature-selective Attention in Frontoparietal Cortex: Multivoxel Codes Adjust to Prioritize Task-relevant Information. Journal of Cognitive Neuroscience, 29(2), 310-321.

Kahneman, D. (1973). Attention and effort. Englewood Cliffs, NJ: Prentice Hall.

Kamal, B. S., Holman, C., \& de Villers-Sidani, E. (2013). Shaping the aging brain: Role of auditory input patterns in the emergence of auditory cortical impairments. Frontiers in Systems Neuroscience, 7, 52.

Kelley, C. M., \& Sahakyan, L. (2003). Memory, monitoring, and control in the attainment of memory accuracy. Journal of Memory and Language, 48, 704-721.

Koeritzer, M. A., Rogers, C. S., Van Engen, K. J., \& Peelle, J. E. (In press). The impact of age, background noise, semantic ambiguity, and hearing loss on recognition memory for speech. Journal of Speech, Language, and Hearing Research.

Kuchinsky, S. E., Vaden Jr., K. I., Keren, N. I., Harris, K. C., Ahlstrom, J. B., Dubno, J. R., \& Eckert, M. A. (2012). Word intelligibility and age predict visual cortex activity during word listening. Cerebral Cortex, 22, 1360-1371.

Kujawa, S. G., \& Liberman, M. C. (2009). Adding insult to injury: Cochlear nerve degeneration after "temporary" noise-induced hearing loss. Journal of Neuroscience, 29, 14077-14085.

Lash, A., Rogers, C. S., Zoller, A., \& Wingfield, A. (2013). Expectation and entropy in spoken word recognition: Effects of age and hearing acuity. Experimental Aging Research, 39, 235-253.

Laver, G. D., \& Burke, D. M. (1993). Why do semantic priming effects increase in old age? A meta-analysis. Psychology and Aging, 8(1), 34-43.

Liebenthal, E., Binder, J. R., Spitzer, S. M., Possing, E. T., \& Medler, D. A. (2005). Neural substrates of phonemic perception. Cerebral Cortex, 15, 1621-1631.

Ling, L. L., Hughes, L. F., \& Caspary, D. M. (2005). Age-related loss of the GABA synthetic enzyme glutamic acid decarboxylase in rat primary auditory cortex. Neuroscience, 132, 1103-1113. 
Lotto, A. J., Hickok, G. S., \& Holt, L. L. (2009). Reflections on mirror neurons and speech perception. Trends in Cognitive Sciences, 13, 110-114.

McCabe, D. P., Roediger, H. L. I., McDaniel, M. A., Balota, D. A., \& Hambrick, D. Z. (2010). The relationship between working memory capacity and executive functioning: Evidence for a common executive attention construct. Neuropsychology, 24, 222-243.

McCoy, S. L., Tun, P. A., Cox, L. C., Colangelo, M., Stewart, R., \& Wingfield, A. (2005). Hearing loss and perceptual effort: Downstream effects on older adults' memory for speech. Quarterly Journal of Experimental Psychology, 58(1), 22-33.

Melton, A. W. (1963). Implications of short-term memory for a general theory of memory. Journal of Verbal Learning and Verbal Behavior, 2, 1-21.

Merchant, S. N., \& Nadol, J. B. (2010). Schuknecht's pathology of the inner ear (Third Edition ed.). Shelton, CT: People's Publishing House.

Mitchell, P., Gopinath, B., Wang, J. J., McMahon, C. M., Schneider, J., Rochtchina, E., \& Leeder, S. R. (2011). Five-year incidence and progression of hearing impairment in an older population. Ear and Hearing, 32, 251-257.

Morrell, C. H., Gordon-Salant, S., Pearson, J. D., Brant, L. J., \& Fozard, J. L. (1996). Age- and gender-specific reference ranges for hearing level and longitudinal changes in hearing level. Journal of the Acoustical Society of America, 100(4, Pt 1), 1949-1967.

Multhaup, K. S., Balota, D. A., \& Cowan, N. (1996). Implications of aging, lexicality, and item length for the mechanisms underlying memory span. Psychonomic Bulletin and Review, $3(1), 112-120$.

Näätänen, R., Paavilainen, P., Rinne, T., \& Alho, K. (2007). The mismatch negativity (MMN) in basic research of central auditory processing: a review. Clinical Neurophysiology, $118(12), 2544-2590$.

Neely, J. H. (1977). Semantic priming and retrieval from lexical memory: Roles of inhibitionless spreading activation and limited-capacity attention. Journal of Experimental Psychology: General, 106, 226-254.

Nelson, T. O., \& Narens, L. (1990). Metamemory: A theoretical framework and some new findings. In G. H. Bower (Ed.), The psychology of learning and motivation (Vol. 26, pp. 125-173). New York: Academic Press.

Neta, M., Miezin, F. M., Nelson, S. M., Dubis, J. W., Dosenbach, N. U. F., Schlaggar, B. L., \& Petersen, S. E. (2015). Spatial and temporal characteristics of error-related activity in the human brain. Journal of Neuroscience, 35, 253-266.

Park, D. C., Royal, D., Dudley, W., \& Morrell, R. (1988). Forgetting of pictures over a long retention interval in young and older adults. Psychology and Aging, 3(1), 94-95.

Park, D. C., Smith, A. D., Lautenschlager, G., Earles, J. L., Frieske, D., Zwahr, M., \& Gaines, C. L. (1996). Mediators of long-term memory performance across the life span. Psychology and Aging, 11(4), 621-637.

Parkinson, S. R., \& Perey, A. (1980). Aging, digit span, and the stimulus suffix effect. Journal of Gerontology, 35(5), 736-742.

Paul, B. T., Bruce, I. C., \& Roberts, L. E. (2017). Evidence that hidden hearing loss underlies amplitude modulation encoding deficits in individuals with and without tinnitus. Hearing Research, 344, 170-182.

Peelle, J. E. (2012). The hemispheric lateralization of speech processing depends on what "speech" is: A hierarchical perspective. Frontiers in Human Neuroscience, 6, 309. 
Peelle, J. E. (In press). Listening effort: How the cognitive consequences of acoustic challenge are reflected in brain and behavior. Ear and Hearing.

Peelle, J. E., \& Wingfield, A. (2016). The neural consequences of age-related hearing loss. Trends in Neurosciences, 39, 486-497.

Peelle, J. E., Johnsrude, I. S., \& Davis, M. H. (2010a). Hierarchical processing for speech in human auditory cortex and beyond. Frontiers in Human Neuroscience, 4, 51.

Peelle, J. E., Troiani, V., Wingfield, A., \& Grossman, M. (2010b). Neural processing during older adults' comprehension of spoken sentences: Age differences in resource allocation and connectivity. Cerebral Cortex, 20, 773-782.

Peelle, J. E., Troiani, V., Grossman, M., \& Wingfield, A. (2011). Hearing loss in older adults affects neural systems supporting speech comprehension. Journal of Neuroscience, 31, 12638-12643.

Pichora-Fuller, M. K. (2008). Use of supportive context by younger and older adult listeners: Balancing bottom-up and top-down information processing. International Journal of Audiology, 47, S72-S82.

Pichora-Fuller, M. K., Kramer, S. E., Eckert, M. A., Edwards, B., Hornsby, B. W. Y., Humes, L. E., Lemke, U., Lunner, T., Matthen, M., Mackersie, C. L., Naylor, G., Phillips, N. A., Richter, M., Rudner, M., Sommers, M. S., Tremblay, K. L., \& Wingfield, A. (2016). Hearing impairment and cognitive energy: The framework for understanding effortful listening (FUEL). Ear and Hearing, 37, 5S-27S.

Piquado, T., Isaacowitz, D., \& Wingfield, A. (2010a). Pupillometry as a measure of cognitive effort in younger and older adults. Psychophysiology, 47, 560-569.

Piquado, T., Cousins, K. A. Q., Wingfield, A., \& Miller, P. (2010b). Effects of degraded sensory input on memory for speech: Behavioral data and a test of biologically constrained computational models. Brain Research Bulletin, 1365, 48-65.

Plomp, R., \& Mimpen, A. M. (1979). Speech-reception threshold for sentences as a function of age and noise level. Journal of the Acoustical Society of America, 66, 1333-1342.

Power, J. D., \& Petersen, S. E. (2013). Control-related systems in the human brain. Current Opinion in Neurobiology, 23, 223-228.

Price, A. R., Bonner, M. F., Peelle, J. E., \& Grossman, M. (2015). Converging evidence for the neuroanatomic basis of combinatorial semantics in the angular gyrus. Journal of Neuroscience, 35, 3276-3284.

Price, A. R., Peelle, J. E., Bonner, M. F., Grossman, M., \& Hamilton, R. H. (2016). Causal evidence for a mechanism of semantic integration in the angular gyrus as revealed by high-definition transcranial direct current stimulation. Journal of Neuroscience, 36(13), 3829-3838.

Prinz, A. A., Bucher, D., \& Marder, E. (2004). Similar network activity from disparate circuit parameters. Nature Neuroscience, 7(12), 1345-1352.

Profant, O., Balogová, Z., Dezortová, M., Wagnerová, D., Hájek, M., \& Syka, J. (2013). Metabolic changes in the auditory cortex in presbycusis demonstrated by MR spectroscopy. Experimental Gerontology, 48, 795-800.

Rabbitt, P. M. A. (1968). Channel capacity, intelligibility and immediate memory. Quarterly Journal of Experimental Psychology, 20, 241-248.

Rabbitt, P. M. A. (1991). Mild hearing loss can cause apparent memory failures which increase with age and reduce with IQ. Acta Otolaryngolica, 476, 167-176. 
931

932

933

934

935

936

937

938

939

940

941

942

943

944

945

946

947

948

949

950

951

952

953

954

955

956

957

958

959

960

961

962

963

964

965

966

967

968

969

970

971

972

973

974

975

976

Rodd, J. M., Davis, M. H., \& Johnsrude, I. S. (2005). The neural mechanisms of speech comprehension: fMRI studies of semantic ambiguity. Cerebral Cortex, 15, 1261-1269.

Rodd, J. M., Johnsrude, I. S., \& Davis, M. H. (2010). The role of domain-general frontal systems in language comprehension: Evidence from dual-task interference and semantic ambiguity. Brain and Language, 115, 182-188.

Rodd, J. M., Johnsrude, I. S., \& Davis, M. H. (2012). Dissociating frontotemporal contributions to semantic ambiguity resolution in spoken sentences. Cerebral Cortex, 22, 1761-1773.

Rogers, C. S. (2016). Semantic priming, not repetition priming, is to blame for false hearing. Psychonomic Bulletin and Review, 24, 1194-1204.

Rogers, C. S., \& Wingfield, A. (2015). Stimulus-independent semantic bias misdirects word recognition in older adults. Journal of the Acoustical Society of America, 138, EL26.

Rogers, C. S., Jacoby, L. L., \& Sommers, M. S. (2012). Frequent false hearing by older adults: The role of age differences in metacognition. Psychology and Aging, 27, 33-45.

Rogers, C. S., Payne, L., Maharjan, S., Sekuler, R., \& Wingfield, A. (In press). Older adults show impaired modulation of attentional alpha oscillations: evidence from dichotic listening. Psychology and Aging.

Rose, N. S., Myerson, J., Sommers, M. S., \& Hale, S. (2009). Are there age differences in the executive component of working memory? Evidence from domain-general interference effects. Aging, Neuropsychology, and Cognition, 16(6), 633-653.

Rudner, M., \& Ronnberg, J. (2008). The role of the episodic buffer in working memory for language processing. Cognitive Prcessing, 9(1), 19-28.

Salthouse, T. A. (1991). Mediation of adult age differences in cognition by reductions in working memory and speed of processing. Psychological Science, 2(3), 179-183.

Salthouse, T. A. (1996a). General and specific speed mediation of adult age differences in memory. Journal of Gerontology: Psychological Sciences, 51(1), 30-42.

Salthouse, T. A. (1996b). The processing-speed theory of adult age differences in cognition. Psychological Review, 103(3), 403-428.

Scharenborg, O., Weber, A., \& Janse, E. (2015). Age and hearing loss and the use of acoustic cues in fricative categorization. Journal of the Acoustical Society of America, 138(3), 1408-1417.

Sheldon, S., Pichora-Fuller, M. K., \& Schneider, B. A. (2008). Priming and sentence context support listening to noise-vocoded speech by younger and older adults. Journal of the Acoustical Society of America, 123(1), 489-499.

Skipper, J. I., Nusbaum, H., \& Small, S. L. (2005). Listening to talking faces: Motor cortical activation during speech perception. NeuroImage, 25, 76-89.

Skoe, E., Krizman, J., Anderson, S., \& Kraus, N. (2015). Stability and plasticity of auditory brainstem function across the lifespan. Cerebral Cortex, 25(6), 1415-1426.

Smith, A. D. (1977). Adult age differences in cued recall. Developmental Psychology, 13, 326331.

Sommers, M. S., \& Danielson, S. M. (1999). Inhibitory processes and spoken word recognition in young and older adults: The interaction of lexical competition and semantic context. Psychology and Aging, 14, 458-472.

Souchay, C., \& Isingrini, M. (2004). Age related differences in metacognitive control: role of executive functioning. Brain and Cognition, 56(1), 89-99.

Sperling, G. (1960). The information available in brief visual presentations. Psychological Monographs: General and Applied, 74, 1-29. 
977

978

979

980

981

982

983

984

985

986

987

988

989

990

991

992

993

994

995

996

997

998

999

1000

1001

1002

1003

1004

1005

1006

1007

1008

1009

1010

1011

1012

1013

1014

1015

1016

1017

1018

1019

1020

Surprenant, A. M. (2007). Effects of noise on identification and serial recall of nonsense syllables in older and younger adults. Aging, Neuropsychology, and Cognition, 14(2), 126-143.

Tulving, E., \& Schacter, D. L. (1990). Priming and human memory systems. Science, 247(4940), 301-306.

Tun, P. A., O'Kane, G., \& Wingfield, A. (2002). Distraction by competing speech in young and older adult listeners. Psychology and Aging, 17(3), 453-467.

Turner, J. G., Hughes, L. F., \& Caspary, D. M. (2005). Affects of aging on receptive fields in rat primary auditory cortex layer V neurons. Journal of Neurophysiology, 94, 2738-2747.

Vaden Jr., K. I., Kuchinsky, S. E., Ahlstrom, J. B., Dubno, J. R., \& Eckert, M. A. (2015). Cortical activity predicts which older adults recognize speech in noise and when. Journal of Neuroscience, 35, 3929-3937.

Vaden Jr., K. I., Teubner-Rhodes, S., Ahlstrom, J. B., Dubno, J. R., \& Eckert, M. A. (2017). Cingulo-opercular activity affects incidental memory encoding for speech in noise. NeuroImage, 157, 381-387.

Vaden Jr., K. I., Kuchinsky, S. E., Cute, S. L., Ahlstrom, J. B., Dubno, J. R., \& Eckert, M. A. (2013). The cingulo-opercular network provides word-recognition benefit. Journal of Neuroscience, 33, 18979-18986.

Vaden Jr., K. I., Kuchinsky, S. E., Ahlstrom, J. B., Teubner-Rhodes, S. E., Dubno, J. R., \& Eckert, M. A. (2016). Cingulo-opercular function during word recognition in noise for older adults with hearing loss. Experimental Aging Research, 42, 67-82.

Verhaeghen, P., \& Salthouse, T. A. (1997). Meta-analyses of age-cognition relations in adulthood: estimates of linear and nonlinear age effects and structural models. Psychological Bulletin, 122(3), 231-249.

Verhaeghen, P., \& De Meersman, L. (1998). Aging and the Stroop effect: a meta-analysis. Psychology and Aging, 13(1), 120-126.

Verhaeghen, P., Marcoen, A., \& Goossens, L. (1993). Facts and fiction about memory aging: a quantitative integration of research findings. Journal of Gerontology, 48(4), P157-171.

Watkins, K. E., Strafella, A. P., \& Paus, T. (2003). Seeing and hearing speech excites the motor system involved in speech production. Neuropsychologia, 41(8), 989-994.

Waugh, N. C., \& Norman, D. A. (1965). Primary Memory. Psychological Review, 72, 89-104.

Weeks, J. C., \& Hasher, L. (2017). Older adults encode more, not less: evidence for age-related attentional broadening. Aging, Neuropsychology, and Cognition, 1-12.

Wild, C. J., Yusuf, A., Wilson, D., Peelle, J. E., Davis, M. H., \& Johnsrude, I. S. (2012). Effortful listening: The processing of degraded speech depends critically on attention. Journal of Neuroscience, 32, 14010-14021.

Wingfield, A. (2016). Evolution of models of working memory and cognitive resources. Ear and Hearing, 37, 35S-43S.

Wingfield, A., \& Stine-Morrow, E. A. L. (2000). Language and speech. In F. I. M. Craik \& T. A. Salthouse (Eds.), The handbook of aging and cognition (2nd ed ) (pp. 359-416). Mahwah, NJ: Lawrence Erlbaum Associates.

Wingfield, A., Tun, P. A., \& McCoy, S. L. (2005). Hearing loss in older adulthood: What it is and how it interacts with cognitive performance. Current Directions in Psychological Science, 14, 144-148. 
1021

1022

1023

1024

1025

1026

1027

1028

1029

1030

1031

1032

1033

1034

1035

1036

1037
Xia, J., Nooraei, N., Kalluri, S., \& Edwards, B. (2015). Spatial release of cognitive load measured in a dual-task paradigm in normal-hearing and hearing-impaired listeners. Journal of the Acoustical Society of America, 137(4), 1888-1898.

Zacks, R. T., Hasher, L., \& Li, K. Z. H. (2000). Human memory. In F. I. M. Craik \& T. A. Salthouse (Eds.), The Handbook of Aging and Cognition (Second ed., pp. 293-357). Mahwah, New Jersey: Lawrence Erlbaum Associates.

Zekveld, A. A., \& Kramer, S. E. (2014). Cognitive processing load across a wide range of listening conditions: Insights from pupillometry. Psychophysiology, 51, 277-284.

Zekveld, A. A., Kramer, S. E., \& Festen, J. M. (2010). Pupil response as an indication of effortful listening: The influence of sentence intelligibility. Ear and Hearing, 31, 480490.

Zekveld, A. A., Kramer, S. E., \& Festen, J. M. (2011). Cognitive load during speech perception in noise: The influence of age, hearing loss, and cognition on the pupil response. Ear and Hearing, 32, 498-510.

Ziegler, J., \& Pylkkanen, L. (2016). Scalar adjectives and the temporal unfolding of semantic composition: An MEG investigation. Neuropsychologia, 89, 161-171. 